\title{
Encontros entre trabalhadores: a Universidade Aberta à Terceira Idade como espaço para confrontação de memórias
}

Meetings between workers: the Open University Program for Seniors as space for confronting memories

\section{Introdução}

Este texto pretende destacar algumas questões que emergiram do desenvolvimento da atividade de extensão realizada na Universidade Estadual do Oeste do Paraná (UNIOESTE). Trata-se do projeto "Produzindo Memórias e Histórias", realizado entre agosto de 2011 e junho de 2012. Esse trabalho ocorreu vinculado ao programa Universidade Aberta à Terceira Idade (UNATI), o qual, em 2011, era instituído no Campus de Marechal Cândido Rondon, Paraná.

Ao considerarmos a cidade de Marechal Cândido Rondon como espaço privilegiado para as discussões do projeto, reconhecemos que esse território contava com 52 anos de municipalização. Portanto, ao avaliarmos a idade dos participantes (acima de 55 anos) e a narrativa que fizeram de suas trajetórias, lidamos, em grande medida, com pessoas que, em algum momento do percurso da vida, haviam se dirigido para essa localidade.

Diante disso, procuramos suscitar durante o projeto uma reflexão sobre os sentidos e as condições dessas mudanças, assim como avaliações que faziam sobre o viver nesse novo lugar. Entendíamos que esse ponto de partida permitiria evidenciar situações como trabalho e vida familiar, tratando de valores e interesses que orientaram condutas, associando-os a um universo mais amplo da experiência social no campo e na cidade.

Ao realizarmos os debates, noções polêmicas vinculadas a migrantes e pioneiros, relações campo/cidade e práticas de trabalho e cuidado com filhos vieram à tona. Assim como determinada condição de classe foi formulada como terreno comum e de distinção social, algo que sugeriu tensões sobre modos de morar e trabalhar e tam-

\author{
Sheille Soares Freitas' e Carlos \\ Meneses de Sousa Santos ${ }^{2}$
}

\section{Resumo}

Propomos apresentar algumas questões suscitadas a partir do desenvolvimento do projeto de extensão intitulado Produzindo Memórias e Histórias", vinculado ao Programa Universidade Aberta à Terceira Idade - UNATI. Esse programa é uma atividade institucional realizada pela Universidade Estadual do Oeste do Paraná UNIOESTE. Entre agosto de 2011 e junho de 2012, promovemos algumas reflexões a partir de documentos, como entrevistas orais, programas de rádio, fichas de assistência social, entre outros. O interesse foi debater os sentidos expressos na produção desses materiais, confrontando valores e atuações dos sujeitos que protagonizaram as relações evidenciadas. O texto destaca a identificação de uma condição de classe, comum aos trabalhadores, mas também expõe compreensões e encaminhamentos distintos ao se tratar essa condição em nossas próprias trajetórias.

Palavras-chave: Trabalhadores. UNATI. Memórias

Área Temática: Educação

Linha de Extensão: Educação e Terceira Idade 
bém diante de sociabilidades e movimentação social, pautando, nesse bojo, atuações frente à escolarização formal e sobre o atendimento médico e hospitalar.

Como historiadores, construímos um caminho de reflexão que percebia, nos possíveis participantes das oficinas, trajetórias que se constituíram como representativas de um processo histórico vivido pela sociedade brasileira, tendo como temporalidade o período posterior à segunda metade do século XX. E, como modo de pautar a discussão desse processo, propusemos o debate e análise de documentos, o que permitiu um contato diferenciado com questões ordinárias e contraditórias do universo social em questão.

Para tal, utilizamos entrevistas orais (produzidas pelos pesquisadores proponentes do projeto), notícias de programas de rádio (programa Frente Ampla de Notícias, rádio Difusora, Marechal Cândido Rondon-PR), fichas de assistência social (Relatórios de Acompanhamento produzido por servidores do Centro de Referência e Assistência Social - CRAS), entre outros documentos.

Essas fontes permitiram associar e distinguir certas experiências em um conjunto mais amplo da sociedade, assim como o trabalho com fotografias (indicadas pelos participantes) e matérias apresentadas na mídia. Um procedimento metodológico que potencializou os participantes a se depararem com as contradições, interesses e distinções na presença de determinados sujeitos na produção da cidade de Marechal Cândido Rondon.

Com esse repertório, a pretensão do texto foi sendo construída, procurando destacar a identificação de uma condição de classe, comum a muitos trabalhadores, assim como expor compreensões e encaminhamentos distintos ao se tratar dessa condição, observando que relações de poder eram expressas nesse convívio social e como interpretamos e nos posicionamos ao tratar dessa dinâmica histórica.

Ao trabalhar com esses materiais, destacamos um obituário apresentado no noticiário "Frente Ampla de Notícias", veiculado pela Rádio Difusora do Paraná, atuante em Marechal Cândido Rondon desde 1966. O anúncio, intitulado "Fim da vida de um pioneiro", foi transmitido em 31 de janeiro de 1968. O programa formulou a seguinte narrativa:
Aquele que entrou corajosamente em um lugar para rasgar selva a peito aberto fazendo com que a mais frondosa árvore sentisse o tilintar do seu machado impiedoso, buscasse e rebuscasse lascar até cair o tronco grande onde o pioneiro sentava-se logo após por alguns instantes em seu pequeno descanso de entre em meio a derrubada. Esta é a vida de pioneiro. Pioneiro é aquele homem de coragem, ou muita coragem que não há perigo com qual se defronte que não une todas as suas forças para que torne tudo esclarecido. Vindo do Rio Grande do Sul, foi alojar-se na localidade de Linha São Cristóvão. Ali apontavam calos por sobre calos em mãos alvas de um grande amigo que sabíamos ter muita saúde e vontade de trabalhar. João é o seu nome, o nome daquele que transformou sua união conjugal em grande família que hoje sente a perda de um ente querido. Viver tantos anos no desempenho do desbravamento, lutando contra temperaturas e contra o tempo no feitio de obras de onde provinham o seu sustento. Designado a sentar junto ao senhor, João morreu como um pioneiro. Cumprir o seu dever de pioneiro para morrer como tal. ${ }^{1}$

Indicamos a notícia, formulada pela rádio, como modo de evidenciarmos uma noção recorrentemente proposta ao se falar do processo de constituição da cidade. A noção de "pioneiro" é atribuída como modo de qualificar e destacar a suposta preponderância de determinados sujeitos que vieram para Marechal Cândido Rondon, os quais, por meio de suas atuações, expressariam o que é apresentado como o próprio "desempenho do desenvolvimento".

Essa elaboração busca atribuir virtude a certos empreendimentos e, mesmo que tensionados socialmente, eles são enunciados, muitas vezes, como inevitáveis e inquestionáveis, além de serem alardeados como algo desejado e esperado por toda a sociedade.

Ao colocarmos essa visão em discussão, uma das participantes do projeto, uma senhora de aproximadamente 60 anos (proprietária de uma pequena área rural junto com seu esposo), logo indicou sua inserção social e vínculo a essa narrativa:

essa notícia aí era o meu vizinho [risos]... É... a introdução fala muito da derrubada das árvores, porque ele, na verdade, ele era dono de uma serraria, né? Então, acho que justo por isso que eles introduziram a questão de lascar árvores e 
tudo... que foi um dos primeiros... das primeiras serrarias do município de Rondon... Era a dele ali, em São Cristóvão [linha São Cristóvão, Distrito de Margarida]. (TRANSCRIÇÃO da atividade VI. Projeto Produzindo Memórias e Histórias. UNATI/PROEX. Universidade Estadual do Oeste do Paraná, Campus de Marechal Cândido Rondon. Marechal Cândido Rondon, 27.03.2012, p. 02. Transcrição realizada pela monitora Tatiane K. M. Silva.)

A Senhora que se pronunciou chegou à área rural de São Cristóvão - então município de Toledo, hoje pertencente a Marechal Cândido Rondon - em 1952. Ainda criança, com menos de um ano de idade, acompanhava os pais, que vinham de Santa Catarina:

Tudo começou com uma parte de um bolão da Loteria Federal que meu pai ganhou em 1949... Com esse capital ele realizou o sonho de adquirir uma área de terras no Oeste do Paraná, para criar gado... Ficamos em Toledo até que o pai derrubou a mata e construiu o galpão, dividido em partes (moradia, paiol para o milho e estrebaria para as vacas de leite). Ali vivi minha infância... (ISADORA (pseudônimo). Texto autobiográfico. Projeto Produzindo Memórias e Histórias. UNATI/PROEX. Universidade Estadual do Oeste do Paraná, Campus de Marechal Cândido Rondon. Marechal Cândido Rondon, 10.04.2012, p. 1)

Quando nos confrontamos com essa memória, entendida como elaboração das experiências e expectativas de pequenos proprietários, reconhecemos logo o público que ocuparia as salas da Universidade quando esta instituição declarou estar aberta às pessoas com mais de 55 anos. Encontramo-nos com uma ex-primeira-dama e uma ex-secretária de educação do município, além de um engenheiro e um professor, todos aposentados. Talvez procurassem reencontrar o que lhes foi familiar no percurso de suas vidas, ou ainda, a consagração dos caminhos construídos nesses últimos 50 anos.

Entendíamos, portanto, que nossas pretensões iniciais (as quais pareciam supor encontros com trabalhadores que tivessem atuado como empregados desses sujeitos), não seriam realizadas nesse projeto. No entanto, tínhamos a oportunidade de dialogar com pequenos proprietários, como Isadora, cuja família teria conseguido o ca- pital para compra das terras após terem sido premiados em um bolão da Loteria Federal.

Ao problematizarmos a celebração de certa noção de pioneiro aprendemos a nos confrontar com a automoralidade de pequenos proprietários, fundamentalmente os que chegaram a empregar-se com terceiros ou aqueles que apenas com muitas dificuldades se constituíram como patrões de outros trabalhadores.

Assim, não ignoramos a exploração mantida no modo como construíram suas relações de poder, reconhecendo posturas que lhes mantiveram como pequenos proprietários. Mas, por sua vez, passamos a destacar o universo de contradições que compunha suas experiências e permeariam os debates nas oficinas.

A automoralidade de Isadora propunha certa legitimidade às benesses de sua família, por investir "na cidade" e potencializar postos de trabalhos "a quem precisava". A partir de sua narrativa, sugeriu refletirmos sobre como lidou com a identificação de dificuldades nesse processo, por vezes compartilhadas com um conjunto mais amplo de trabalhadores e, por outras, não impedindo que formulasse sua distinção de classe.

Ao realizar o debate sobre as imagens atribuídas a trabalhadores que vieram para Marechal Cândido Rondon, chamamos a atenção para os que não usufruíam da condição de proprietários, os quais não figuravam na categoria de "pioneiros". Nesse caminho, destacamos assalariados, meeiros, agregados e diaristas. Essas imagens foram novamente evidenciadas a partir de transmissões do programa Frente Ampla de Notícias. A exibição ocupa agora o quadro de "Ocorrências policiais", apresentando a seguinte visibilidade:

Recebemos da Guarda Noturna local as ocorrências que vamos dar abaixo: $\mathrm{O}$ guarda Joaquim... prendeu na noite de $1^{\circ} \ldots$ os indivíduos Dimas e Agostinho, por estarem embriagados, sem onde dormir e sem documentação de espécie alguma. Na Delegacia de Polícia foi providenciado acomodação para ambos, que passaram a noite como hóspedes do Estado. Constatamos realmente, de algum tempo para cá o aumento do número de aves de arribação que, além de não possuírem documentação alguma, de maneira geral são "gambás". O policiamento se encarrega dos mesmos, mas isso só não basta para curá-los. ${ }^{2}$ 
As "aves de arribação", encontradas "sem onde dormir e sem documentação", foram acomodadas na delegacia de polícia, "como hóspedes do Estado". Provavelmente, os policiais encontraram homens que, nas restritas vindas à cidade, devido à condição de empregados rurais, aproveitavam para se embriagar, reconhecendo aí algum divertimento. Quando indicamos esse sentido como possibilidade histórica na experiência de muitos trabalhadores, percebemos, contudo, que o questionamento dessa prática não guardava exclusividade apenas nas ações de patrões e do Estado, mas também de familiares e outros trabalhadores. Logo ouvimos a seguinte consideração durante o debate:

Esse caso aqui... foram tratados desses indivíduos como indigentes, porque na verdade, de repente, eles eram trabalhadores... eles fizeram história também na nossa região. Por exemplo, isso aconteceu em 67; em 50, quando o meu falecido pai abriu em São Cristóvão, ele adquiriu uma terra... uma área bastante grande, e os filho... só tinha as três meninas pequenas, eu era a bebê de colo. Mas aí vinha muito o pessoal do Paraguai, andarilhos que saíram do Paraguai... que cometeram algum delito lá... e pra não ficá preso lá - porque as delegacias lá eram diferentes do que é hoje, né? Geralmente eram maltratados - então eles fugiam pro Brasil. E eles... ali, eles trabalhavam honestamente... e eles sabiam que... porque eles não tinham mais aonde ir. Então, eu sei que meu pai ele chegava a ter 20 paraguaios trabalhando na terra, porque ele derrubô uma base de umas dez colônias de terra, e plantô tudo colonião, porque o objetivo do meu pai era criá gado, né? Então, era morros e tudo. Ele pegô uma terra quebrada... e tinha uns paraguaios lá, e uns foram pro Paraguai buscá a esposa também. E o meu pai, naquela época... eles faziam uns ranchinhos mesmo... eles pegavam sapé e coqueiro e faziam... Mais era gente de bem! Só que eles tinham isso... o pai pagava e eles bebiam, porque eles não sabiam... Daí, entre eles, eles se provocavam, mas com nós não, nós nunca tivemos uma troca de palavra com essa gente. Sempre foi gente de bem... e nós fomos criados com eles... Porque daí a mãe pegô as paraguaias pra ajudá em casa, pra cuidá das crianças, né? Mas era assim, meu pai foi gente que se respeitava, foi gente de credo, apesar de ser de posses, né? E essas pessoas... a minha mãe sempre foi de dizer assim... passavam os andarilhos lá em casa... então os outros vizinhos, que vieram do sul, eles tinham assim um pouco de medo, re- jeição, né? E a minha mãe tinha uma área grande, ela recebia essas pessoas. Elas chegavam lá em casa a mãe tratava... e nós sentávamos ao lado dos andarilhos pra vê eles comê... dava a impressão de que eles não eram gente, sabe? Porque a mãe cuidava muito bem de nós, eles tão maltrapilhos assim... (TRANSCRIÇÃO da atividade VIII. Projeto Produzindo Memórias e Histórias. UNATI/PROEX. Universidade Estadual do Oeste do Paraná, Campus de Marechal Cândido Rondon. Marechal Cândido Rondon, 24.04.2012, p. 08. Transcrição realizada pela monitora Tatiane K. M. Silva.)

Sendo assim, "de repente, eles eram trabalhadores". Aceitar pensar sobre essa possibilidade permitiu que Isadora assentasse sua avaliação a partir de sua própria experiência, pois "eles tinham isso... o pai pagava e eles bebiam, porque eles não sabiam". A condescendência é pautada na imagem de classe, uma vez que não há dúvidas sobre a compreensão de que "essa gente" é o grupo dos que recebem para trabalhar, enquanto o pai paga pelo trabalho realizado. A relação classista permite estabelecer o distanciamento das posições ocupadas na convivência desigual ao mesmo tempo em que aponta essa convivência como algo valoroso: "meu pai foi gente que se respeitava, foi gente de credo, apesar de ser de posses, né?".

A benevolência indicada articula exploração e vitimização, sendo que reúne, na mesma análise, a indignação com o noticiário da Rádio - atribuindo legitimidade à atuação policial que tratou os sujeitos mencionados como "indigentes" - e, ao mesmo tempo, aponta que o pai chegou a ter 20 trabalhadores em suas terras, os quais teriam desmatado aproximadamente 10 colônias, algo em torno de 250 hectares.

Essa composição parece supor uma relação marcada pelo equilíbrio de interesses, na qual tanto os trabalhadores quanto os empregadores teriam sido beneficiados de modo satisfatório. Principalmente porque o pai "adquiriu uma terra... uma área bastante grande, e os filho... só tinha as três meninas pequenas". Já os trabalhadores eram associados a andarilhos, fugitivos de delitos, maltrapilhos. Uma gente que era vista na desigualdade. $\mathrm{O}$ que, ao destacar o acolhimento nas terras da família, a participante procurava amenizar o pouco que se fazia por eles, sugerindo que isso já indicava muito diante da trajetória que esses trabalhadores apresentavam. 
O suposto consenso entre patrão e empregados apresenta esses sujeitos convivendo no interior da casa de "área grande", espaço diferente daquele "ranchinho de sapé e coqueiro" em terra quebrada, o qual se constituiu no lugar destinado aos trabalhadores. A relação, firmada como de proximidade, apresenta um ambiente de interação ambígua, "nós fomos criados com eles... Porque daí a mãe pegô as paraguaias pra ajudá em casa, pra cuidá das crianças, né?".

Contudo, o aparente consenso, revelado no olhar patronal, não nos parece retórico ou cínico, apesar de ser a própria experiência da exploração. Acreditamos de fato que há algo de distintivo nessa automoralidade. Distinção que evidencia a divergência de condutas firmadas nas ações de proprietários, sobretudo quando se trata da relação com subalternos.

Porém, essa determinada ordem de envolvimento certamente não anulou a desigualdade da relação. Pelo contrário, talvez tenha potencializado a crueza das imagens do encontro entre desiguais: "dava a impressão de que eles não eram gente, sabe?". Esse parece o termo da condescendência classista, parece ser esse o ápice da automoralidade patronal.

Foi desse universo de considerações que emergiu o espaço de confrontações de memórias estabelecido no decorrer das atividades. Essa moralidade foi desafiada a pensar o lugar social de onde era erigida, foi instigada a avaliar a perversidade e as contradições de suas argumentações. Ao instigar que os participantes se colocassem sobre essas questões, retomávamos elementos de suas trajetórias, polemizando determinada tranquilidade interpretativa que sugeria esse processo como um percurso natural de esforço e "conquistas".

Mesmo que apontassem limites em vivências da infância e adolescência, ou mesmo destacassem conhecer de perto certas condições que problematizam o distanciamento de classe erigido em suas falas naquele momento, isto não impediu que formulassem um julgamento a partir do valor capitalista de empenho e sucesso individual, contradizendo, em muitos momentos, o universo conflituoso e de pressões em que se concatenam as possibilidades e alternativas de trabalhadores empobrecidos.

Quando apresentamos a notícia de que o "Lions Clube homenageou [...] os pioneiros", transmitida pela Rádio Difusora em meados de 1978, esperávamos deslegitimar a linguagem celebrante circunscrita no elogio das façanhas e da grandeza de determinados pioneiros. Uma produção de memória que ativava a emasculação de um amplo conjunto de personagens:

Durante a reunião festiva de ontem, o Lions Clube prestou significativamente, uma homenagem aos pioneiros que vieram construir Mal. C. Rondon... [a] reunião festiva de ontem... contou com a totalidade dos membros do clube terminando com um jantar nas dependências do Concórdia... Lembrou dona Alice [uma das pioneiras homenageadas] que aqui, tudo era mato, céu e os bichos, mas havia a necessidade de acreditar em Deus e assim, todos os problemas foram superados, pela vontade e pela coragem, sobretudo pelas palavras de conforto de um para com o outro, nos piores momentos. Grávida, dona Alice não sabia que estava gerando gêmeos que nasceram numa choupana na localidade de Porto Britânia com o auxilio de uma parteira de 75 anos que somente falava o guarani. ${ }^{3}$

Atuações como essa compõem uma genealogia que localiza as dificuldades no momento da fundação da cidade, construindo a partir desse marco inaugural uma temporalidade de conquistas e melhorias na qual "todos os problemas foram superados". Nessa pauta estruturante aparecem os personagens do enredo narrado: protagonistas e coadjuvantes, mocinhos e vilões, todos dispostos de modo a expor uma cronologia do caminho certo, destacando a trilha que recompõe a importância da homenagem e dos homenageados para que houvesse uma cidade próspera.

Dona Alice (a protagonista destemida, temente a Deus e perseverante) e a velha parteira sem nome (que trazia o inconveniente de só falar o guarani) apontavam essa ambiguidade. Talvez esta personagem obscurecida tivesse algo a dizer sobre a compreensão de que "todos os problemas foram superados", ou ainda, que as palavras de conforto trocadas entre os "desbravadores" na noite festiva não sugeriam uma alteração compartilhada na vida daqueles que trabalhavam de casa em casa prestando serviços aos donos de terra.

Foi ao mencionar as dificuldades de Alice com a gravidez que a parteira foi inserida nessa relação, e não por compor o conjunto daqueles 
que produziam formas de viver durante aqueles primeiros anos de emancipação rondonense. Essa distinção foi percebida pela participante do projeto como algo que retirou o lugar tranquilo da narrativa personificada da pioneira:

Participante: Como colocaram da parteira que nem falaram?!... pena que não se colocou o nome dela... porque ela foi a parteira...

Coordenador 1: Mas ela não era parte dos que seriam homenageados!

Participante: Pois é... a parteira Lica, que ela fez todos os partos ali na região Oeste.

Coordenador 1: Mas ela não era pioneira!

Participante: Ela não era pioneira... é e ela não era bem vista, porque ela era uma Guarani.

Coordenador 2: É... mas era necessária, né?

Participante: A parteira Lica fez todos os partos ali... depois que veio outras parteiras... mas inicialmente era a Lica... Ela podia ter sido lembrada, né?

Coordenador 2: Mas por que não foi lembrada?! (TRANSCRIÇÃO da atividade VIII. Projeto Produzindo Memórias e Histórias. UNATI/PROEX. Universidade Estadual do Oeste do Paraná, Campus de Marechal Cândido Rondon. Marechal Cândido Rondon, 24.04.2012, p. 09. Transcrição realizada pela monitora Tatiane K. M. Silva.)

Mais que protestar contra a censura das biografias dos subalternos ou se indignar com a ausência de seus nomes em ruas e prédios públicos, trata-se aqui de indicar a derrota de valores e interesses sustentados e aspirados por esses sujeitos, não apenas porque eles padeceram em uma temporalidade passada, diante da qual restaria agora folclorizá-los em salas de museus, apontando-os como resquícios de um arcaico que fora deixado para trás. Ao contrário, interessa-nos retomar determinados valores e intenções, atualizá-los e tomá-los como nossos, porque reconhecemos a permanência da relação de exploração que compartilhamos e porque desejamos superá-1a4.

A noção de "não ser bem vista" deixa transparecer uma relação que se manteve na enunciação dos homenageados e na fala da participante do projeto. Lica, a guarani, não podia traduzir o universo de empenho e formação da sociedade rondoniense, ainda que sua trajetória indicasse e até fosse reconhecida pela participante do projeto com esse teor. A presença guarani era sinônimo da ausência de descendência europeia, indício de trabalhadores sem renda fixa e sem investimentos para serem capitalizados no município. Eles não poderiam atender à proposição construída sobre os eleitos para o pioneirismo, a qual procurava no paternalismo a sustentação de um slogan de homogeneidade e avanço no qual a exploração e o empobrecimento não se fazem ver e notar. ${ }^{5}$

Os sujeitos dessa relação desigual, que experimentam as agruras da produção desse "avanço", são extirpados constantemente da narrativa hegemônica para não desautorizar o universo de atuação e iniciativas de controle social. A automoralidade de classe construiu a pauta de questões a serem alteradas em situações como essa sem evidenciar a confrontação de classes que intermediava a proposição: resolver a ausência de atendimento médico na localidade e proporcionar estradas e transporte que permitissem o contato mais eficaz com Toledo e "doutores".

A representatividade da parteira Lica nessas relações indica que sua atuação e historicidade expõem o lugar daqueles que nem sempre foram vistos como gente e que são impingidos a ocupar o campo, ou da exceção, ou de um contingente exótico à origem do lugar, quando não perigoso à sociedade. Contudo, a avaliação desse processo aponta que essas formulações e pressões às relações classistas não se limitaram às primeiras décadas de constituição da cidade.

Ao discutirmos uma ficha do Centro de Referência de Assistência Social - CRAS, a formulação em questão trazia Diana, mãe de Leiriel. A mulher de 18 anos tem Dario como seu marido, pai do garoto de um mês e 13 dias. $O$ menino nasceu em Marechal Cândido Rondon - PR, cidade em que moravam fazia 11 meses. Apesar de indicar ter habilidade como manicure, Diana se encontrava desempregada. Em 28 de outubro de 2010 apenas Dario estava empregado.

O marido, de 26 anos, veio à cidade trabalhar como motorista da empresa Agrícola Horizonte, que tem como atividade privada a industrialização de produtos agrícolas, principalmente trigo, mandioca e soja, a partir dos quais produz farinhas, féculas e rações. $O$ casal saiu da cidade de Cascavel-PR, distante aproximadamente $80 \mathrm{~km}$, em busca de emprego, que oferecia o rendimento mensal de $\mathrm{R} \$ 700,00$. Contudo, eles 
se depararam com dificuldades ao se instalarem em Marechal Cândido Rondon. Diana, ao lidar com essas pressões, buscou a Assistência Social da prefeitura, uma atuação que foi registrada nos seguintes termos:

28/10/2010 - Solicitou cesta básica por estarem passando dificuldades financeiras; o esposo quebrou o dedo e Diana teve gastos com farmácia, ainda teve infecção urinária (...);

21/02/2011 - Encaminhada para o SSE [Serviço Sócio Educativo] de 0 a 6 anos;

03/03/2011 - Recebeu cesta básica e fez inscrição no Curso de Aperfeiçoamento Doméstico (...);

12/04/2011 - Não compareceu no Curso em Serviço de Aperfeiçoamento Doméstico. (DIANA (pseudônimo). [Fichas de cadastro e anotação]. Marechal Cândido Rondon, 28.10.2010. Cadastro no Centro de Referência de Assistência Social. Documentação consultada em março de 2011, CRAS, Pasta 2 - Bairro Higienópolis.)

Entendemos que a situação vivida por Diana se estabelece enquanto aspectos da condição de classe conhecida por milhares de trabalhadores na contemporaneidade. A necessidade do emprego, as dificuldades com a criação dos filhos, assim como a limitação para mobilizar recursos em favor da própria saúde, evidenciam uma experiência histórica marcada pela exploração. Uma exploração constantemente tensionada nas ações desses sujeitos, na qual percorrer cidades e pressionar o Estado vêm se constituindo como dimensões da movimentação social dos trabalhadores, uma evidência do modo como a condição de classe desses sujeitos vem sendo tratada politicamente.

O trabalho de Santos destaca como a atuação de trabalhadores junto à Promotoria Pública não aponta uma conformação ao assistencialismo estatal, ou mesmo o reconhecimento dessa atuação como sua representatividade isenta de relações de poder. $\mathrm{O}$ autor sugere, trabalhando com ações para atendimento médico hospitalar, que os trabalhadores reconhecem o universo de desigualdades que compõe as relações classistas, inclusive na atuação da Promotoria 5 .

Contudo, a tentativa de mensurar, classificar e tipificar o modo de vida dos trabalhadores em níveis cada vez mais variados de pobreza, tendo em vista as pressões que esses sujeitos vêm promovendo por uma condição de classe mais favorável, vem provocando, nas ações do Estado, a proposição de "situações" de "assistência social". Desse modo, o que é expresso como condição comum na vida dos trabalhadores sofre o esforço de ser percebido e tratado como casuísmos provocados por eventualidades individualizadas.

Por certo que gastos com farmácia não são, muitas das vezes, custos constantes, mas, quando exigidos, quase sempre desconsertam orçamentos bastante limitados. Assim, quebrar um dedo e/ou sofrer de infecção urinária expõe trabalhadores a situações limite diante de uma condição constante de pressão ao modo como vivem, limites esses que são valorados frente às necessidades não contempladas, o que em uma sociedade de mercado é muitas vezes traduzido pontualmente como dificuldades financeiras, tal como apreendido e apresentado na avaliação da assistente social.

No entanto, a ampliação da noção sintética de "dificuldades financeiras" aparece nas práticas e nas expectativas dos trabalhadores. A solicitação da cesta básica, atuação construída por Diana, compõe a preocupação com o custo do aluguel, onde a casa de madeira, com quatro cômodos, exige o valor de $\mathrm{R} \$ 300,00$ mensais; que associado aos $R$ \$20,00 de água, $R$ \$ 50,00 de luz, $\mathrm{R} \$ 45,00$ do gás e $\mathrm{R} \$ 12,00$ dos créditos para o telefone celular limitam a alimentação e o vestuário, os quais foram estimados em R $\$ 293,00$ durante o mês.

A confrontação dos gastos com a renda é um dos modos utilizados pelo Estado para diagnosticar o grau de pobreza dos trabalhadores, assim como a necessidade ou não da sua "assistência". Nesse sentido, Diana ao tentar conseguir a cesta básica por meio da assistência social, sugere-nos tratar de uma questão mais ampla do que um problema individual, haja vista que somente no ano de 2010, segundo o próprio CRAS, a situação de 694 famílias foi analisada. Mesmo numericamente, tendemos a considerar como expressiva a quantidade dessas atuações, principalmente se falamos de uma cidade com pouco mais de $45 \mathrm{mil}$ habitantes.

Claro que, ao tomarmos como referência os números do CRAS, ainda precisamos considerar a possibilidade de muitas famílias não terem conseguido sequer serem classificadas em "situação de 
assistência”, não sendo nem mesmo cadastradas para avaliação. Essa consideração parece importante, pois o documento, entendido como expressão dessa relação (entre trabalhadores e Estado) precisa ser compreendido como pauta da relação de desigualdade que o fez emergir.6

Além das atividades do Serviço Socioeducativo indicadas a Diana pelo CRAS, este órgão articula e coordena diversos programas que se remetem à realidade enfrentada por trabalhadores. Há uma promoção enfática e benevolente de tal entidade, algo que foi destaque nas matérias de jornais da cidade, quando de sua inauguração como espaço vinculado às ações da Secretaria Municipal de Assistência Social.7

Frequentar um dos programas ao qual se está associado é um passo necessário para conseguir benefícios, assim como para mantê-los. No caso de Diana os R\$22,00 do Programa Bolsa família exigiam que ela enfrentasse a condescendência classista de psicólogos e assistentes sociais indicando o que é supostamente necessário para educar e moralizar trabalhadores empobrecidos e seus filhos. Ainda assim, os auxílios foram alcançados por ela após 124 dias de empenho.

Contudo, a conquista da cesta básica em particular só foi possível diante da promessa de se fazer presente no Curso de Serviço de Aperfeiçoamento Doméstico, um compromisso que foi descumprido pela trabalhadora, comprometendo futuras conquistas. Talvez tenha considerado outros caminhos para lidar com as dificuldades vividas em sua condição de classe, talvez tenha se permitido perder a paciência com os ensinamentos dos que se julgam a elite educada dos trabalhadores, os quais, muitas vezes, valoram-se enquanto uma espécie de classe média, diferenciando-se no conjunto dos homens e mulheres que vivem de seu próprio trabalho.

Um debate frequente na sociedade brasileira veio à tona no projeto ao tratar da ficha do CRAS: a assistência aos trabalhadores empobrecidos trouxe posições conflitantes, indicando um campo de tensão aberto nas relações contemporâneas, apontando valores e interesses dissidentes.

Participante 1: É... os gastos... não sobram um vintém para o algo a mais, né?! ... Mas... aí é por falta da parte dela, né? Se ela fosse compare- cer... participar desse curso de aperfeiçoamento... e tudo, né? Também não queria nada com nada, né? [...]

Participante 2: É... às vezes a gente vê questões e a gente não analisa. Mas olhando agora, ela parece que não tinha saída, né? Porque esse valor... os gastos mensais extrapolam só nisso aqui... Ela tem que cuidar a criança, como é que ela vai sair, né? A gente não chega a pensar nessas situações todas, né? [...]

Participante 1: Às vezes a gente pensa que as pessoas não querem nada com nada, mas vai ver a realidade deles, né? (TRANSCRIÇÃO da atividade VIII. Projeto Produzindo Memórias e Histórias. UNATI/PROEX. Universidade Estadual do Oeste do Paraná, Campus de Marechal Cândido Rondon. Marechal Cândido Rondon, 24.04.2012, p. 07. Transcrição realizada pela monitora Tatiane K. M. Silva.)

Acreditamos que os participantes do projeto, os quais enfrentam o processo de envelhecimento e certas alterações na condição de interlocutores na sociedade, tiveram o que dizer sobre as práticas de desigualdade experimentadas socialmente nos últimos 50 anos e sobre o recolocar de suas atuações e interpretações do vivido. Por isso, avaliamos que eles perceberam e vivenciaram tensões envolvendo diferentes dimensões do universo social, as quais foram fomentadas por interesses e valores sustentados em suas trajetórias e no compartilhar de relações.

Suas visões foram apresentadas a partir de posicionamentos mantidos na historicidade de suas condutas, ou ainda na reavaliação dessas perante um conjunto de pressões (expressos nas fontes e debates) que traziam certos elementos que não estavam na centralidade de suas narrativas ou explicações, mas que potencializaram a reflexão sobre a realidade.

Ao instigar tal campo reflexivo, esperamos evidenciar contradições e disputas de memórias ${ }^{8}$, pois, ao tratarmos neste texto das provocações interpretativas que o projeto fomentou, trazemos também ações e posicionamentos que continuam interpelando o desejo de uma sociedade mais justa. ${ }^{9}$

\section{Nota dos Autores}

Essa produção foi elaborada a partir dos resultados do projeto de extensão que foi proposto 
e executado pelos autores. As fontes de pesquisa discutidas nos encontros e também, as transcrições (realizadas pela bolsista) dos debates promovidos com os participantes serviram de repertório de análise. Os autores foram responsáveis pela revisão e adequação do texto às normas para publicação.

\section{Referências}

1. FIM da vida de um pioneiro. Frente Ampla de Notícias. Marechal Cândido Rondon: Rádio Difusora do Paraná, 31 jan. 1968. Programa de Rádio.

2. OCORRÊNCIAS policiais. Frente Ampla de Notícias, Marechal Cândido Rondon: Rádio Difusora do Paraná, 04 fev. 1967. Programa de Rádio.

3. LIONS Clube homenageou ontem os pioneiros. Frente Ampla de Notícias. Marechal Cândido Rondon: Rádio Difusora do Paraná, 02 ago. 1978. Programa de Rádio.

4. THOMPSON, E. P. A miséria da teoria ou um planetário de erros (uma crítica ao pensamento de Althusser). Rio de Janeiro: Zahar Editores, 1981

5. SAATKAMP, Venilda et al. Desafios, lutas e conquistas: história de Marechal Cândido Rondon. Cascavel: ASSOES. TE, 1984.

6. SANTOS, Carlos M. S. Uberlândia, cidade em disputa: relações classistas em fins do século XX e início do século XXI. Tempos Históricos, Marechal Cândido Rondon, v. 14, p. $172-197,1$ sem. 2010

7. NOVA sede do CRAS será inaugurada amanhã em Marechal Cândido Rondon. AquiAgora.net. Marechal Cândido Rondon, 18.02.2010. Disponível em: $<$ http://www.aquiagora. net/verNoticia.php?nid=5842>. Acesso em: 29 jul. 2011.

8. FENELON, Déa R. et. al. (Org.). Muitas Memórias, Outras Histórias. São Paulo: Olho d'Água, 2004.

9. FONTANA, Josep. História: análise do passado e projeto social. Bauru, SP: EDUSC, 1998.

\section{Abstract}

We intend to present some questions arising from the development of the Community Project entitled "Making Memories and Histories, linked to the Open University Program for the Elderly - UNATI. This program is an institutional activity carried out by the State University of Paraná - UNIOESTE. From August 2011 to June 2012, some discussions were promoted based on documents such as oral interviews, radio programs, written records and others. We aimed at debating the meanings expressed in the production of these documents, by confronting subjects values and actions. These subjects play an important role within the relationships which were evidenced. The text not only highlights the identification of a working class condition but also exposes the different understandings and referrals when treating this condition in our own trajectories.

Keywords: Workers; UNATI; Memories 